\title{
The Influence of an Overactive Bladder on Falling: A Study of Females Aged 40 and Older in the Community
}

\author{
Seung-Jin Moon, Yong Tae Kim, Tchun Yong Lee, Hongsang Moon ${ }^{1,4}$, Mi Jung Kim², Shin Ah Kim³, Bo Youl Choi ${ }^{3,4}$ \\ Department of Urology, Hanyang University College of Medicine, Seoul; \\ ${ }^{1}$ Department of Urology, Hanyang University Guri Hospital, Guri; \\ ${ }^{2}$ Department of Rehabilitation Medicine, Hanyang University College of Medicine, Seoul; \\ ${ }^{3}$ Department of Preventive Medicine, Hanyang University College of Medicine, Seoul; \\ ${ }^{4}$ Center for Healthy Aging and Longevity of Hanyang University Institute of Aging Society, Seoul, Korea
}

\begin{abstract}
Purpose: An overactive bladder $(\mathrm{OAB})$ affects a person's quality of life. Patients who suffer from $\mathrm{OAB}$ run to the toilet frequently to prevent incontinence, and this behavior increases their risk of falling and fear of falling. This study evaluated the influence of $\mathrm{OAB}$ on falls and concern about falling in females aged 40 and over living in urban and rural communities.

Methods: We conducted a population-based cohort study using King's Health Questionnaire (KHQ), the Korean version of Falls Efficacy Scale-International (KFES-I) and a questionnaire regarding falls, in females aged 40 and over in Guri city and Yangpyeong county. The data from 514 responders were analyzed. The definition of OAB was 'moderately' or 'a lot' of urgency, or urge incontinence in KHQ. Falls was defined as experience of falls in the last year. High fear of falling was defined as a score of 24 or over in KFES-I. The factors were analyzed by the exact chi-square test and Student's t-test. The multivariate logistic regression model was adopted in order to examine the effects of $\mathrm{OAB}$ on falls and concern about falling.

Results: Of the 514 responders, 98 fitted the criterion of OAB. Eighty-nine (17.3\%) of the responders had experienced falls in the last year: twenty-seven (27.5\%) in the group with $\mathrm{OAB}$ and $62(14.9 \%)$ in the group without OAB. There was a significant association between falls and $\mathrm{OAB}$ (odds ratio [OR], 1.76; 95\% confidence interval [CI], 1.00 to 3.08; $\mathrm{P}=0.0485$ ), and between high fear of falling and $\mathrm{OAB}(\mathrm{OR}, 2.72 ; 95 \% \mathrm{CI}, 1.42$ to $5.20 ; \mathrm{P}=0.0024)$.

Conclusions: Urgency and symptoms of urge incontinence increase the risk of falls in women aged 40 or older in the community. Early diagnosis and proper treatment may prevent falls and improve quality of life in OAB patients.
\end{abstract}

Keywords: Urinary bladder; Overactive; Urinary incontinence; Urge; Accidental falls

\section{INTRODUCTION}

The International Continence Society (ICS) defines overactive bladder $(\mathrm{OAB})$ as a condition of urgency with or without urge incontinence, usually with frequency and nocturia, and without any underlying conditions such as infection or metabolic disorders that can induce similar symptoms [1]. Reports of the prevalence of OAB vary. The prevalence in those over 18 was reported to be about $16.5 \%$ in the United States and $16.6 \%$ in those over 40 in Europe [2,3]. According to a report of the Korean Continence Society, the overall prevalence of lower urinary tract symptoms (LUTS) including OAB is $12.2 \%$ in adults and $14.3 \%$ in females. Furthermore prevalence increases with age, and rises to $18.4 \%$ in females over 40 . The overall prevalence of experience of falls is $33-50 \%$ in old age [4-6].

Previous research has identified various risk factors for falls: old age, female gender, visual disturbance, cognitive disorder, low body mass index and others [5,7]. Other risk factors are voiding symptoms of $\mathrm{OAB}$, including urgency and urge incontinence, which causes patients to rush to the toilet and increases the number urinations, and nocturia [8].

Though several previous publications have reported that in-
Corresponding author: Hongsang Moon

Department of Urology, Hanyang University Guri Hospital, 249-1

Gyomun-dong, Guri 471-701, Korea

Tel: +82-31-560-2374 / Fax: +82-31-560-2372

E-mail: moonuro@hanyang.ac.kr

Submitted: February 28, 2011 / Accepted after revision: March 20, 2011
This is an Open Access article distributed under the terms of the Creative Commons Attribution Non-Commercial License (http://creativecommons.org/licenses/by-nc/3.0/) which permits unrestricted non-commercial use, distribution, and reproduction in any medium, provided the original work is properly cited. 
continence and LUTS are significantly correlated with falls, those studies had several limitations. First, the results were inconsistent $[7,9,10]$. Second, they did not distinguish between urge and stress incontinence $[9,10]$ and the validity of the questionnaires used was not confirmed. Also almost all the data concerned people in the West, with little data for Korean women [11].

For this reason we conducted the present study to examine the correlations between $\mathrm{OAB}$ and urgency, urge incontinence, and falls and fear of falling, based on a survey of women over 40 in the Korean community.

\section{MATERIALS AND METHODS}

This study included females over 40 among persons who completed a Community Health Survey (CHS) conducted by the Yangpyeong Health Center and Guri Health Center in 2008. The CHS is a health interview survey conducted on every adult over 19 in 253 health centers nationwide since 2008. The Health Interview Survey covers disease status, use of medicines and healthy living habits. The survey was conducted from September, 2008 to November, 2008, using identical questionnaires and methods. Nearly 800 people were surveyed within the precinct covered by each health center, and the subjects were carefully selected by systematic sampling with probability proportional to size to obtain an accurate representation of the area they were from. After compiling lists of households, sample households were selected by systematic sampling. Eight hundreds and seventy one participants (397 males and 474 females) from Yangpyeong Health Center and 814 participants (357 males and 457 females) from Guri Health Center completed the survey. Further questionnaires on falls and overactive bladders were completed by all females over 40 in the two communities in May, 2009. The response rate from Yangpyeong, a rural area, was $87.8 \%$ (345 respondents out of 393 females) and $68.8 \%$ from Guri, an urban area (190 respondents from $276 \mathrm{fe}-$ males).

The population-based cohort study used King's Health Questionnaire (KHQ), the Korean Falls Efficacy Scale-International (KFES-I) and a questionnaire about falls. We excluded four of the 535 responders because their questionnaires were very incomplete, and 17 because they had had OAB previously diagnosed by a doctor. The data from the remaining 514 responders (182 living in Guri, and 332 in Yangpyeong) were analyzed.

Demographic characteristics of the responders included age, dwelling place, marital status and educational status. Age was divided into 4 groups, 40-49, 50-59, 60-69, and over 70. Dwelling place was divided into urban area (Guri) and rural area (Yangpyeong). Marital status was defined by the presence of a partner, and educational status by the most advanced educational establishment attended: no education, elementary or middle school, high school or more advanced.

Medical characteristics referred to hypertension, cerebro/ cardiovascular disease (stroke, myocardial infarction, and angina) osteoporosis, osteoarthritis diagnosed by a doctor and incontinence.

$\mathrm{OAB}$ was defined as an answer of 'moderately' or 'a lot' of urgency, or urge incontinence in KHQ. Falls was defined as experience of one or more falls in the previous year. High fear of falling was defined as a score of 24 or over in KFES-I. We analyzed the effect of $\mathrm{OAB}$ on falls and concern about falling on the basis of this definition.

We analyzed continuous variables using Student's t-test, and categorical variables using Pearson's chi-square test. We performed multivariate logistic regression to examine the correlation between $\mathrm{OAB}$ and falls and fear of falling, after adjusting for covariants. Statistical analysis was performed with SAS ver. 9.1 (SAS Institute Inc., Cary, NC, USA), and differences with Pvalues of 0.05 or less were considered statistically significant.

\section{RESULTS}

Among the 514 responders, 98 matched the criterion of $\mathrm{OAB}$ and 416 did not. Mean age of responders was 59.2 years; in those with $\mathrm{OAB}$ it was 64.2 years and in those without $\mathrm{OAB}, 58$ years $(\mathrm{P}<0.0001)$. The group with $\mathrm{OAB}$ tended towards absence of partner, low educational status, hypertension, cerebro/ cardio vascular disease, and osteoarthritis $(\mathrm{P}<0.005)$. The two groups did not differ significantly in dwelling place, or incidence of diabetes and osteoporosis (Table 1).

Of the responders 89 (17.3\%) had experienced falls in the last year, and there was a significant difference in the proportion experiencing falls in the last year in the two groups: 27 $(27.5 \%)$ in the OAB group vs. $62(14.9 \%)$ in the non-OAB group $(\mathrm{P}=0.0029)$. The same was true with respect to having a high level of concern about falling: $36(37.9 \%)$ in the $\mathrm{OAB}$ group vs. $54(13.1 \%)$ in the non-OAB group $(\mathrm{P}<0.0001)$ (Table 2).

We performed multivariate logistic regression analysis to determine the correlation between $\mathrm{OAB}$ and falls and fear of falling after adjusting for covariants including age, educational sta- 
Table 1. Baseline characteristics of the study subjects by presence or absence of overactive bladder

\begin{tabular}{|c|c|c|c|c|}
\hline Variables & $\begin{array}{c}\text { Total } \\
\text { subjects } \\
(\mathrm{n}=514)\end{array}$ & $\begin{array}{c}\text { With } \\
\text { OAB } \\
(n=98)\end{array}$ & $\begin{array}{c}\text { Without } \\
\text { OAB } \\
(n=416)\end{array}$ & P-value ${ }^{a)}$ \\
\hline Age (yr) & $59.2^{\text {b) }}$ & $64.2^{\mathrm{b})}$ & $58.0^{\mathrm{b})}$ & $<0.0001^{c)}$ \\
\hline $40-49$ & $143(27.8)$ & $13(13.2)$ & $130(31.2)$ & $<0.0001$ \\
\hline $50-59$ & $122(23.7)$ & $19(19.4)$ & $103(24.8)$ & \\
\hline $60-69$ & $127(24.7)$ & $24(24.5)$ & $103(24.8)$ & \\
\hline$\geq 70$ & $122(23.8)$ & $42(42.9)$ & $80(19.2)$ & \\
\hline Area & & & & 0.1391 \\
\hline Urban (Guri) & $182(35.4)$ & $41(41.8)$ & $141(33.9)$ & \\
\hline Rural (Yangpyeong) & $332(64.6)$ & $57(58.2)$ & $275(66.1)$ & \\
\hline Marital Status & & & & 0.0225 \\
\hline Married & $368(71.6)$ & $61(62.2)$ & $307(73.8)$ & \\
\hline Single $^{\mathrm{d})}$ & $146(28.4)$ & $37(37.8)$ & $109(26.2)$ & \\
\hline Education & & & & 0.0003 \\
\hline High school or more & $183(35.6)$ & $19(19.3)$ & $164(39.4)$ & \\
\hline $\begin{array}{l}\text { Elementary or } \\
\text { middle school }\end{array}$ & $200(38.9)$ & $42(42.9)$ & $158(38.0)$ & \\
\hline Illiteracy & $131(25.5)$ & $37(37.8)$ & $94(22.6)$ & \\
\hline \multicolumn{5}{|c|}{ Self-reported doctor's diagnosis of disease } \\
\hline Diabetes & & & & 0.3706 \\
\hline No & $454(88.3)$ & $84(85.7)$ & $370(88.9)$ & \\
\hline Yes & $60(11.7)$ & $14(14.3)$ & $46(11.1)$ & \\
\hline Hypertension & & & & 0.0276 \\
\hline No & $352(68.5)$ & $58(59.2)$ & $294(70.7)$ & \\
\hline Yes & $162(31.5)$ & $40(40.8)$ & $122(29.3)$ & \\
\hline \multicolumn{4}{|c|}{ Cerebrovascular/cardiovascular disease ${ }^{\mathrm{e})}$} & 0.0051 \\
\hline No & $486(94.5)$ & $87(88.8)$ & $399(95.9)$ & \\
\hline Yes & $28(5.5)$ & $11(11.2)$ & $17(4.1)$ & \\
\hline Osteoporosis & & & & 0.9746 \\
\hline No & $462(89.9)$ & $88(89.8)$ & $374(89.9)$ & \\
\hline Yes & $52(10.1)$ & $10(10.2)$ & $42(10.1)$ & \\
\hline Osteoarthritis & & & & 0.0027 \\
\hline No & $408(79.4)$ & $67(68.4)$ & $341(82.0)$ & \\
\hline Yes & $106(20.6)$ & $31(31.6)$ & $75(18.0)$ & \\
\hline
\end{tabular}

Values are presented as number (\%).

$\mathrm{OAB}$, overactive bladder.

a) By chi-square test. ${ }^{\text {b) }}$ Mean (yr). ${ }^{\text {c) By t-test. }}{ }^{\text {d) }}$ Widowed, divorced or separated, never married. ${ }^{\text {e)}}$ Stroke, angina, my-ocardial infarction.

tus, presence of partner, living area and underlying disease. The analysis showed that there were statistically significant correlations between $\mathrm{OAB}$ and falls $(\mathrm{OR}, 1.76 ; 95 \% \mathrm{CI}, 1.00$ to $3.08 ; \mathrm{P}=$ 0.0485), and between $\mathrm{OAB}$ and high fear of falling (OR, 2.72; 95\% CI, 1.43 to $5.20 ; \mathrm{P}=0.0024$ ) (Tables 3,4 ).

Factors including age, presence of partner, educational status,
Table 2. Characteristics of the study subjects by presence or absence of overactive bladder

\begin{tabular}{|c|c|c|c|c|}
\hline Variables & $\begin{array}{l}\text { Total subjects } \\
\quad(\mathrm{n}=514)\end{array}$ & $\begin{array}{l}\text { With OAB } \\
\quad(n=98)\end{array}$ & $\begin{array}{l}\text { Without OAB } \\
\qquad(\mathrm{n}=416)\end{array}$ & P-value ${ }^{\text {a) }}$ \\
\hline \multicolumn{4}{|c|}{ Experience of fall in the last year } & 0.0029 \\
\hline No & $425(82.7)$ & $71(72.5)$ & $354(85.1)$ & \\
\hline Yes & $89(17.3)$ & $27(27.5)$ & $62(14.9)$ & \\
\hline \multicolumn{4}{|c|}{ Fear of falling conducted by KFES-I ${ }^{\text {b) }}$} & $<0.0001$ \\
\hline $16-23$ & $418(82.3)$ & $59(62.1)$ & $359(86.9)$ & \\
\hline$\geq 24$ & $90(17.7)$ & $36(37.9)$ & $54(13.1)$ & \\
\hline
\end{tabular}

Values are presented as number (\%).

$\mathrm{OAB}$, overactive bladder; KFES-I, Korean version of Falls Efficacy ScaleInternational questionnaire.

${ }^{\text {a) }}$ By chi-square test. ${ }^{\text {b) }}$ Total subjects differ because of some missing values.

hypertension, cerebro/cardio vascular disease and osteoarthritis, which were associated with $\mathrm{OAB}$ in Pearson's chi-square test, were not significantly correlated with $\mathrm{OAB}$ in multivariate logistic regression analysis. However high fear of falling was associated with age $(\mathrm{P}<0.0001)$ and low educational status $(\mathrm{P}=$ 0.008 ) in the multivariate logistic regression analysis (Table 4).

\section{DISCUSSION}

The prevalence of falls increases with age, and the risk of falling is higher in women than men. In addition complications such as fractures due to falls can evoke severe morbidity or mortality in the old and post-menopausal. Risk factors for falls are old age, female gender, visual disturbance, cognitive disorder, use of tranquilizers, etc. Voiding difficulties including incontinence are also known risk factors [5,7].

$\mathrm{OAB}$, which is one of the causes of incontinence, is defined as a condition of urgency with or without urge incontinence, usually with frequency and nocturia. $\mathrm{OAB}$ reduces the quality of life of affected persons, an aspect that has received attention only recently [12]. Voiding symptoms of OAB include urgency, urge incontinence, frequency and nocturia. The changes of behavior induced by these voiding symptoms are considered to affect the likelihood of falls, and this idea is supported by several studies showing that incontinence is a risk factor for falls $[4,9,10,13]$. However those studies did not discriminate between urge and stress incontinence, and used questionnaire that had not been validated. Therefore they have limitations with regard to supporting the correlation of $\mathrm{OAB}$ with falls.

$\mathrm{KHQ}$ is a voiding questionnaire that can assess the severity and effect on quality of life of voiding symptoms; it is of proven 
Table 3. Effects of overactive bladder and known risk factors for falls

\begin{tabular}{|c|c|c|c|}
\hline \multirow{2}{*}{ Risk factors } & \multicolumn{3}{|c|}{ Experience of falls in the last year } \\
\hline & OR & $95 \% \mathrm{CI}$ & P-value \\
\hline Overactive bladder & & & 0.0485 \\
\hline No & 1.00 & & \\
\hline Yes & 1.76 & $(1.00-3.08)$ & \\
\hline Age (yr) & & & 0.0776 \\
\hline $40-49$ & 1.00 & & \\
\hline $50-59$ & 0.68 & $(0.30-1.57)$ & \\
\hline $60-69$ & 1.68 & $(0.74-3.82)$ & \\
\hline$\geq 70$ & 2.11 & $(0.80-5.54)$ & \\
\hline Area & & & 0.1493 \\
\hline Urban (Guri) & 1.00 & & \\
\hline Rural (Yangpyeong) & 0.68 & $(0.40-1.15)$ & \\
\hline Marital status & & & 0.9221 \\
\hline Married & 1.00 & & \\
\hline Single ${ }^{\text {a) }}$ & 1.03 & $(0.59-1.80)$ & \\
\hline Education & & & 0.2252 \\
\hline High school or more & 1.00 & & \\
\hline Elementary or middle school & 1.61 & $(0.82-3.16)$ & \\
\hline Illiteracy & 1.05 & $(0.46-2.42)$ & \\
\hline \multicolumn{4}{|c|}{ Self reported doctor's diagnosis of disease } \\
\hline Diabetes & & & 0.1571 \\
\hline No & 1.00 & & \\
\hline Yes & 1.63 & $(0.83-3.20)$ & \\
\hline Hypertension & & & 0.8356 \\
\hline No & 1.00 & & \\
\hline Yes & 1.06 & $(0.62-1.82)$ & \\
\hline \multicolumn{3}{|c|}{ Cerebrovascular / cardiovascular disease ${ }^{\mathrm{b})}$} & 0.2318 \\
\hline No & 1.00 & & \\
\hline Yes & 0.52 & $(0.18-1.52)$ & \\
\hline Osteoporosis & & & 0.8630 \\
\hline No & 1.00 & & \\
\hline Yes & 1.07 & $(0.50-2.27)$ & \\
\hline Osteoarthritis & & & 0.5662 \\
\hline No & 1.00 & & \\
\hline Yes & 1.18 & $(0.67-2.08)$ & \\
\hline
\end{tabular}

OR, odds ratio; CI, confidential interval.

${ }^{a)}$ Widowed, divorced or separated, never married. ${ }^{\text {b) }}$ Stroke, angina, myocardial infarction.

validity and reproducibility in assessing incontinence and $\mathrm{OAB}$ $[14,15]$. In addition, the Falls Efficacy Scale (FES) was designed to assess the degree of perceived efficacy in avoiding a fall during relatively non-hazardous daily activities [16]. However, because the questions are restricted to basic and instrumental ac-
Table 4. Effects of overactive bladder and known risk factors on fear of falling

\begin{tabular}{|c|c|c|c|}
\hline \multirow{2}{*}{ Risk factors } & \multicolumn{3}{|c|}{ Fear of falling } \\
\hline & OR & $95 \% \mathrm{CI}$ & P-value \\
\hline Overactive bladder & & & 0.0024 \\
\hline No & 1.00 & & \\
\hline Yes & 2.72 & $(1.43-5.20)$ & \\
\hline Age (yr) & & & $<0.0001$ \\
\hline $40-49$ & 1.00 & & \\
\hline $50-59$ & 1.50 & $(0.13-17.51)$ & \\
\hline $60-69$ & 15.03 & $(1.78-127.2)$ & \\
\hline$\geq 70$ & 17.15 & $(38.13-336.6)$ & \\
\hline Area & & & 0.2203 \\
\hline Urban (Guri) & 1.00 & & \\
\hline Rural (Yangpyeong) & 1.57 & $(0.76-3.22)$ & \\
\hline Marital status & & & 0.9221 \\
\hline Married & 1.00 & & \\
\hline Single ${ }^{\text {a) }}$ & 1.00 & $(0.54-1.86)$ & \\
\hline Education & & & 0.0079 \\
\hline High school or more & 1.00 & & \\
\hline Elementary or middle school & 1.56 & $(0.46-5.24)$ & \\
\hline Illiteracy & 3.83 & $(1.14-12.9)$ & \\
\hline \multicolumn{4}{|c|}{ Self reported doctor's diagnosis of disease } \\
\hline Diabetes & & & 0.3255 \\
\hline No & 1.00 & & \\
\hline Yes & 1.46 & $(0.69-3.10)$ & \\
\hline Hypertension & & & 0.5834 \\
\hline No & 1.00 & & \\
\hline Yes & 1.19 & $(0.65-2.18)$ & \\
\hline \multicolumn{3}{|c|}{ Cerebrovascular / cardiovascular disease ${ }^{\mathrm{b})}$} & 0.7421 \\
\hline No & 1.00 & & \\
\hline Yes & 1.18 & $(0.44-3.14)$ & \\
\hline Osteoporosis & & & 0.4774 \\
\hline No & 1.00 & & \\
\hline Yes & 0.76 & $(0.35-1.63)$ & \\
\hline Osteoarthritis & & & 0.1482 \\
\hline No & 1.00 & & \\
\hline Yes & 1.57 & $(0.85-2.88)$ & \\
\hline
\end{tabular}

OR, odds ratio; CI, confidential interval.

${ }^{\text {a)} W i d o w e d, ~ d i v o r c e d ~ o r ~ s e p a r a t e d, ~ n e v e r ~ m a r r i e d . ~}{ }^{\text {b) }}$ Stroke, angina, myocardial infarction.

tivities of daily living, the answers do not reflect individual differences, and the sensitivity of the questionnaire in detecting loss of confidence in maintaining balance in elderly persons capable of functioning in daily life is low $[17,18]$.

To avoid this weakness, Powell and Myers [18] designed an 
activities-specific balance confidence $(A B C)$ scale. The greater item-responsiveness of the $\mathrm{ABC}$ scale makes it more suitable for detecting loss of balancing confidence in more highly functioning seniors [19]. Yardley et al. [20] designed the Falls Efficacy Scale-International (FES-I), which combines the advantages of FES in assessing indoor activity and the advantage of $\mathrm{ABC}$ in measuring outdoor activity. FES-I has greater validity and reliability than the FES in assessing fear of falling. Also the reliability of KFES-I for measuring the risk of falling has been supported by examination of its internal consistency and the testretest method [21].

In our study, we found that $27.5 \%$ of females aged 40 or over who answered 'moderately' or 'a lot' with regard to urgency or urge incontinence in the $\mathrm{KHQ}$, had experienced falls, and $\mathrm{OAB}$ increased the risk of falls 1.76 fold compared to the group without $\mathrm{OAB}$. The falls due to $\mathrm{OAB}$ may be explained in several ways. Sufferers may hurry to the toilet to avoid social embarrassment due to urge incontinence, or their increased frequency of urination, or nocturia, may disrupt their sleeping pattern, diminish daytime wakefulness and lead to visual disturbance at night [22].

Interestingly, the frequencies of underlying diseases that are known risk factors for falls such as diabetes, cerebro/cardio vascular disease and osteoarthritis did not differ between our two groups. Also general expectations of falls was not associated with other medical condition. This finding may have been due to a selection bias that excluded females who could not visit the public health center where they lived due to gait disturbance caused by medical or neurologic disorders or severe osteoarthritis.

In previous studies, although the correlation between treatment of $\mathrm{OAB}$ and reduction of risk of falls was not established, the necessity of treatment of $\mathrm{OAB}$ to reduce the risk of falls was mentioned [8,22-24]. Treatment of OAB may reduce the risk of falls because the behavioral changes resulting from $\mathrm{OAB}$ increase the risk of falls.

In our study, age, presence of partner, educational status, hypertension, cerebro/cardio vascular disease and osteoarthritis, were associated with $\mathrm{OAB}$, but domicile, diabetes and osteoporosis were not. The lack of effect of domicile implies that socioeconomic status and mode of life have insignificant effects on $\mathrm{OAB}$ compared to underlying disease; it follows that consideration of underlying disease should take priority over consideration of socioeconomic status in the screening and diagnosis of $\mathrm{OAB}$, and in the prevention and treatment of falls due to $\mathrm{OAB}$.
The group with $\mathrm{OAB}$ contained 1.5 times more persons lacking partners than the group without $\mathrm{OAB}$, and showed a tendency towards lower educational status, but these two effects were not statistically significant. These results suggest that partners and preventive education are ineffective in preventing falls. Hence more understanding, assistance and multifarious preventive educational measures may be needed to prevent falls.

Fear of falling is defined as a psychological state of anxiety of falling in elderly people who have experienced falls. It restricts the activities of the elderly and induces body weakness, and the risk of falling increases with body weakness [25]. In the present study, the proportion of those in the group with $\mathrm{OAB}$ with high fear of falling was $37.9 \%, 2.7$ fold higher than in the group without OAB. This implies that experience of falls due to urgency or urge incontinence induces fear of falling. In other words, $\mathrm{OAB}$ as a disease entity affects not only voiding symptoms but also individual physical and psychological status, and so can affect an individual's entire quality of life. Furthermore, a substantial increase of direct costs can be anticipated due to the increase in the aging population [26] and the overall prevalence of lower urinary tract symptoms including $\mathrm{OAB}$ has not changed in the last several years [27]. This means that we should change our conception of $\mathrm{OAB}$ from a disease restricted to individuals' voiding symptoms to a social health problem in need of prevention and treatment.

This study has some limitations. It did not use common definition of $O A B$. In this study, $O A B$ was defined as an answer of 'moderately' or 'a lot' of urgency, or urge incontinence in KHQ to promote convenience of survey in large scaled cohort study and prevent misunderstanding about $\mathrm{OAB}$ in the olds and illiterates. It did not assess the correlation between treatment of $\mathrm{OAB}$ and decreased risk of falls, which is the context of $\mathrm{OAB}$ and falls, or, due to a selection bias, the correlation between underlying disease and falls.

On the other hand, the study had some strengths. It revealed correlations of $\mathrm{OAB}$ with falls and fear of falling, and between severity of urgency or urge incontinence and falls and fear of falling, by using the KHQ and KFES-I questionnaires whose validity and reliability have been established. Moreover the outcomes can be generalized because the responders were part of the general population living in urban and rural areas. Moreover, the data are trustworthy because they were collected with the help of a well-trained assistant.

Early treatment and preventive education may be needed to reduce the risk of falls and to improve the quality of life of 
women suffering from OAB. In future, to identify the correlation between falls and other risk factors, more aggressive methods of data collection such as telephone surveys or home visits may be needed to reduce selection bias due to gait disturbance. A large-scale multicenter prospective study should be performed to assess the effect of treatment of $\mathrm{OAB}$ on the prevalence of falls and quality of life.

In conclusion, independent of age, educational status, dwelling place, presence of partner and underlying disease, $\mathrm{OAB}$ increases the risk of falls 1.8 fold, and of high fear of falling 2.7 fold, in women aged 40 or older in the community.

Early diagnosis and treatment of $\mathrm{OAB}$, more understanding, assistance by partners and preventive education, may be needed to improve the quality of life and decrease the risk of falls. A large-scale multicenter prospective study should be performed to examine the effect of treatment of $\mathrm{OAB}$ on the prevalence of falls and quality of life.

\section{CONFLICT OF INTEREST}

No potential conflict of interest relevant to this article was reported.

\section{ACKNOWLEDGEMENTS}

This work was supported by the research fund of Hanyang University Institute of Aging Society in 2009.

\section{REFERENCES}

1. Abrams P, Cardozo L, Fall M, Griffiths D, Rosier P, Ulmsten U, et al. The standardisation of terminology of lower urinary tract function: report from the Standardisation Sub-committee of the International Continence Society. Neurourol Urodyn 2002;21:167-78.

2. Stewart WF, Van Rooyen JB, Cundiff GW, Abrams P, Herzog AR, Corey R, et al. Prevalence and burden of overactive bladder in the United States. World J Urol 2003;20:327-36.

3. Milsom I, Abrams P, Cardozo L, Roberts RG, Thüroff J, Wein AJ. How widespread are the symptoms of an overactive bladder and how are they managed? A population-based prevalence study. BJU Int 2001;87:760-6.

4. Tinetti ME, Speechley M, Ginter SF. Risk factors for falls among elderly persons living in the community. N Engl J Med 1988;319: 1701-7.

5. Coutinho ES, Fletcher A, Bloch KV, Rodrigues LC. Risk factors for falls with severe fracture in elderly people living in a middle-income country: a case control study. BMC Geriatr 2008;8:21.

6. Berry SD, Miller RR. Falls: epidemiology, pathophysiology, and relationship to fracture. Curr Osteoporos Rep 2008;6:149-54.

7. van Helden S, Wyers CE, Dagnelie PC, van Dongen MC, Willems G, Brink PR, et al. Risk of falling in patients with a recent fracture. BMC Musculoskelet Disord 2007;8:55.

8. Brown JS, Vittinghoff E, Wyman JF, Stone KL, Nevitt MC, Ensrud $\mathrm{KE}$, et al. Urinary incontinence: does it increase risk for falls and fractures? Study of Osteoporotic Fractures Research Group. J Am Geriatr Soc 2000;48:721-5.

9. Wagner TH, Hu TW, Bentkover J, LeBlanc K, Stewart W, Corey R, et al. Health-related consequences of overactive bladder. Am J Manag Care 2002;8(19 Suppl):S598-607.

10. Tromp E. Risk profiles and preventive measures of falls in elderly persons. Tijdschr Gerontol Geriatr 2002;33:21-5.

11. Cho JP, Paek KW, Song HJ, Jung YS, Moon HW. Prevalence and associated factors of falls in the elderly community. Korean J Prev Med 2001;34:47-54.

12. Kim UH, Kim YH, Kim ME. The prevalence and quality of life of overactive bladder and urinary incontinence in young women. Korean J Urol 2004;45:543-50.

13. Morris V, Wagg A. Lower urinary tract symptoms, incontinence and falls in elderly people: time for an intervention study. Int J Clin Pract 2007;61:320-3.

14. Kelleher CJ, Cardozo LD, Khullar V, Salvatore S. A new questionnaire to assess the quality of life of urinary incontinent women. $\mathrm{Br} J$ Obstet Gynaecol 1997;104:1374-9.

15. Reese PR, Pleil AM, Okano GJ, Kelleher CJ. Multinational study of reliability and validity of the King's Health Questionnaire in patients with overactive bladder. Qual Life Res 2003;12:427-42.

16. Tinetti ME, Richman D, Powell L. Falls efficacy as a measure of fear of falling. J Gerontol 1990;45:P239-43.

17. Tinetti ME, Mendes de Leon CF, Doucette JT, Baker DI. Fear of falling and fall-related efficacy in relationship to functioning among community-living elders. J Gerontol 1994;49:M140-7.

18. Powell LE, Myers AM. The Activities-specific Balance Confidence (ABC) Scale. J Gerontol A Biol Sci Med Sci 1995;50A:M28-34.

19. Cho KY, Lee KY, Jang SH, Kwon IS, Park BJ, Kim MJ. The relationship between Korean Version of Falls Efficacy Scale - International and frequency of falls in the healthy elderly visiting the public health centers. J Korean Acad Rehabil Med 2010;34:342-6.

20. Yardley L, Beyer N, Hauer K, Kempen G, Piot-Ziegler C, Todd C. Development and initial validation of the Falls Efficacy Scale-International (FES-I). Age Ageing 2005;34:614-9. 
21. Park G, Cho B, Kwon IS, Park BJ, Kim T, Cho KY, et al. Reliability and Validity of Korean Version of Falls Efficacy Scale-International (KFES-I). J Korean Acad Rehabil Med 2010;34:554-9.

22. Parsons JK, Mougey J, Lambert L, Wilt TJ, Fink HA, Garzotto M, et al. Lower urinary tract symptoms increase the risk of falls in older men. BJU Int 2009;104:63-8.

23. Brown JS, McGhan WF, Chokroverty S. Comorbidities associated with overactive bladder. Am J Manag Care 2000;6(11 Suppl):S574-9.

24. Hasegawa J, Kuzuya M, Iguchi A. Urinary incontinence and behavioral symptoms are independent risk factors for recurrent and injurious falls, respectively, among residents in long-term care facilities.
Arch Gerontol Geriatr 2010;50:77-81.

25. Tinetti ME, Speechley M. Prevention of falls among the elderly. N Engl J Med 1989;320:1055-9.

26. Reeves P, Irwin D, Kelleher C, Milsom I, Kopp Z, Calvert N, et al. The current and future burden and cost of overactive bladder in five European countries. Eur Urol 2006;50:1050-7.

27. Wennberg AL, Molander U, Fall M, Edlund C, Peeker R, Milsom I. Lower urinary tract symptoms: lack of change in prevalence and help-seeking behaviour in two population-based surveys of women in 1991 and 2007. BJU Int 2009;104:954-9. 